\title{
How to determine atrial situs? Considerations initiated by 3 cases of absent spleen with
a discordant anatomy between bronchi and atria
}

\author{
G. CARUSO AND A. E. BECKER
}

From the Department of Pathological Anatomy, University of Bari, Bari, Italy; and the Department of Pathology, Wilhelmina Gasthuis, University of Amsterdam, Amsterdam, The Netherlands

SUMMARY Three cases have been documented in which abdominal heterotaxy with absent spleen was accompanied by a discordant anatomy between the tracheobronchial tree and the atria. In 1 instance the tracheobronchial anatomy was as in situs inversus but the venous connections and the atrial appendages suggested situs solitus. The second case exhibited a situs solitus anatomy of the tracheobronchial tree, but the morphological features of the atria were mixed up in the sense that the venous connections and atrial septum suggested situs inversus, whereas the atrial appendages were of a right isomeric type. The third case was interesting in showing a symmetrical tracheobronchial tree not accompanied by isomeric atrial appendages. The latter and the atrial septum exhibited situs solitus characteristics, though the venous connections suggested 'situs ambiguus'. Such observations have led us to reconsider the criteria that determine the classification of atrial situs. It is our contention that in cases characterised by major abnormalities in atrial anatomy, particularly with respect to the venous connections, the prime feature for identification of atrial situs would be the morphology of the atrial appendages, which represent the 'true' atrial Anlagen. Positive identification of atrial appendages would also enable a more precise definition of the term 'atrial situs ambiguus'. This term can then be defined as the situs characterised by either bilateral right- or bilateral left-sided morphological characteristics of the atrial appendages, irrespective of the venous connections or atrial septal anatomy.

Identification of atrial situs is the initial step in any segmental analysis and classification of congenital heart malformations (Lev, 1954; Van Praagh et al., 1964a; de la Cruz and Nadal-Ginard, 1972; Van Praagh, 1972; Kirklin et al., 1973; Anderson et al., 1974; Shinebourne et al., 1976; Stanger et al., 1977; Van Praagh, 1977).

According to Lev (1954) and Lev and Rowlatt (1961), identification of atria as either right or left should be based on morphological characteristics. However, since the anatomy of the atria is distorted in many cases of congenital heart disease, the clinical determination of atrial situs may pose a problem, particularly in the presence of heterotaxy of abdominal viscera or a discordance in situs between the abdominal and the thoracic organs. In these circumstances it has been suggested that atrial situs can be inferred from the configuration of the tracheobronchial tree (Landing et al., 1971;

Received for publication 27 July 1978
Partridge et al., 1975), since it is widely accepted that atrial situs corresponds with that of the thoracic organs (Van Praagh et al., 1964a; Van Mierop et al., 1970). Indeed, in patients with a normal spleen only 2 exceptions to this rule have as yet been reported (Clarkson et al., 1972; Liberthson et al., 1973; Brandt and Calder, 1977). However, anatomical studies have disclosed several other exceptions to this 'rule' in the presence of splenic abnormalities, albeit that the various authors do not always emphasise the discrepancy (Freedom and Fellows, 1973; Liberthson et al., 1973; Freedom and Harrington, 1974; Anderson et al., 1976). These exceptions necessitate a reconsideration of the criteria that determine the classification of atrial situs.

It is for this reason that we present 3 patients with absent spleen and discordant anatomy between bronchi and atria, in order to discuss one of the basic questions with respect to the segmental analysis of congenital heart disease, that is, how do we determine atrial situs? 


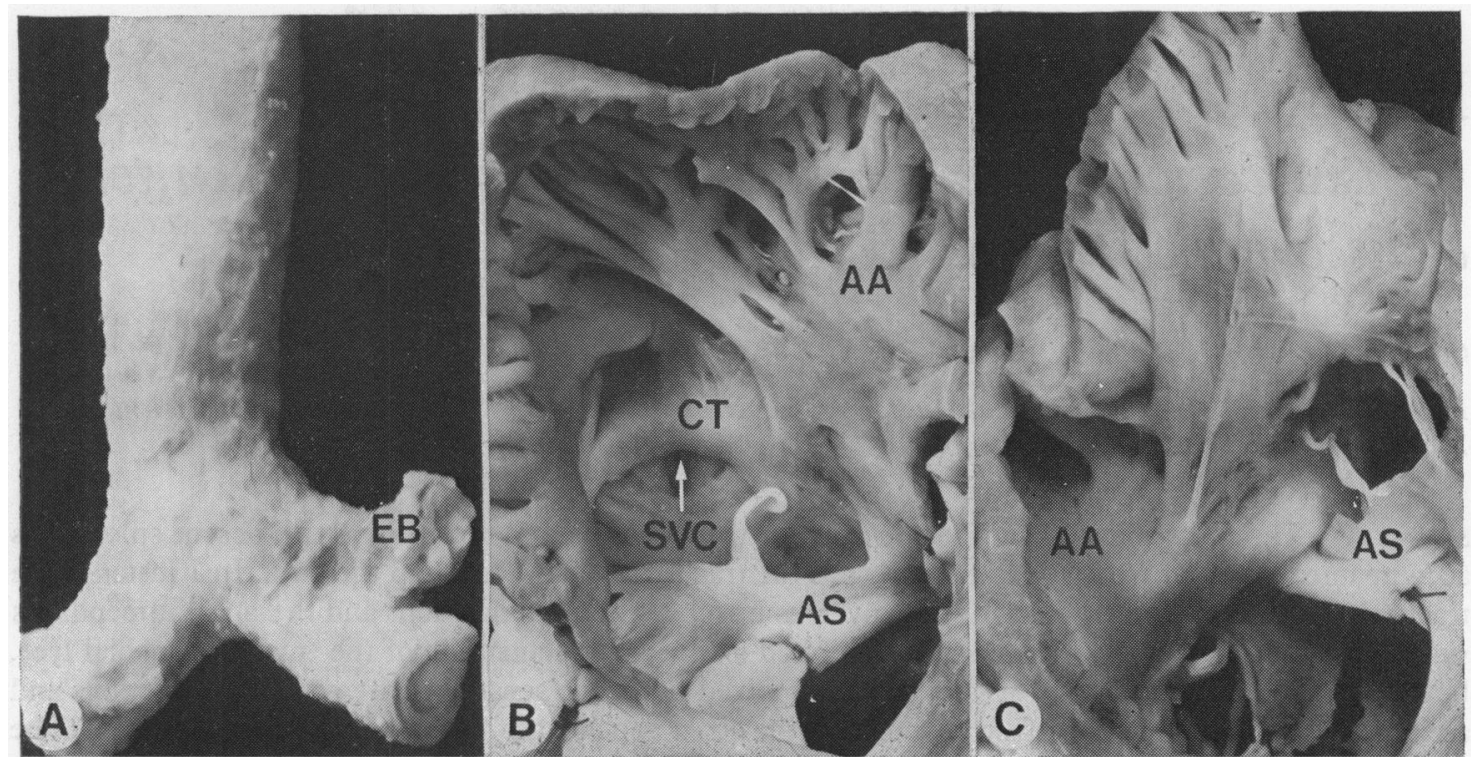

Fig. 1 Case 1. (A) The tracheobronchial bifurcation viewed from anterior. There is an eparterial bronchus $(E B)$ on the left. $(B)$ The opened right-sided atrium; the atrial septum $(A S)$ consists of a thin fenestrated band of endocardial tissue. There is a persistent common atrioventricular canal. The atrial appendage $(A A)$ shows the internal arrangement of pectinate muscles and a crista terminalis $(C T)$, as in a morphological right atrium. The superior caval vein $(S V C)$ and inferior caval vein (not visible in this view) enter this right-sided atrium. $(C)$ The opened left-sided atrium. The atrial appendage $(A A)$ on this side shows the characteristics of a morphological left atrium. Note the deficient atrial septum $(A S)$. The pulmonary veins which connected to this left-sided atrium are not visible.

\section{Case reports}

\section{CASE 1}

A baby girl was admitted to hospital shortly after birth because of episodes of cyanosis. Clinical examination disclosed heterotaxy of the abdominal situs with oligaemic lung fields and laevocardia. The child died at 2 days of age with signs of severe hypoxia from heart failure.

The necropsy confirmed the presence of heterotaxy of the abdominal organs with a centrally positioned symmetrical liver. The spleen was absent. There was agenesis of the right kidney.

The main stem bronchus on the left was short with early origin of an upper lobe bronchus (Fig. 1A). The latter was classified as an eparterial bronchus since it ran 'above', dorsal to the upper lobe pulmonary artery. The right main bronchus looked like a normal left (Fig. 1A). The upper lobe bronchus, in this situation, ran 'below', ventral to the associated upper lobe artery; on which criterion it was identified as the hyparterial bronchus. The terms eparterial and hyparterial for bronchi will be used throughout this paper in their classical meaning, indicating the specific relation between bronchus and artery considered characteristic for right and left-sidedness, respectively. In other words, the anatomy of the bronchi in this case was reversed, suggesting a situs inversus anatomy of the thoracic organs. The right-sided atrial appendage was plump, showing an inner aspect characterised by coarsely arranged, heavy pectinate muscles extending into the apex, while the appendage communicated to the vein receiving part of the atrium through a wide opening, in part delineated by a ridge of muscle, the crista terminalis. The left-sided atrium, on the other hand, had a slender, finger-like external appearance, the inner aspect of which showed parallel arrangement of pectinate muscle not extending fully to the apex, while the appendage connected to the vein received part of the atrium through a relatively small opening without a crista terminalis. The external and internal anatomy of the atrial appendages thus suggested situs solitus, with the morphologically right atrial appendage on the right and the morphologically left atrial appendage on the left (Fig. 1B and C). The inferior caval vein ascended on the right side of the vertebral column to enter the right-sided atrium. There was a right-sided superior caval vein which entered the 


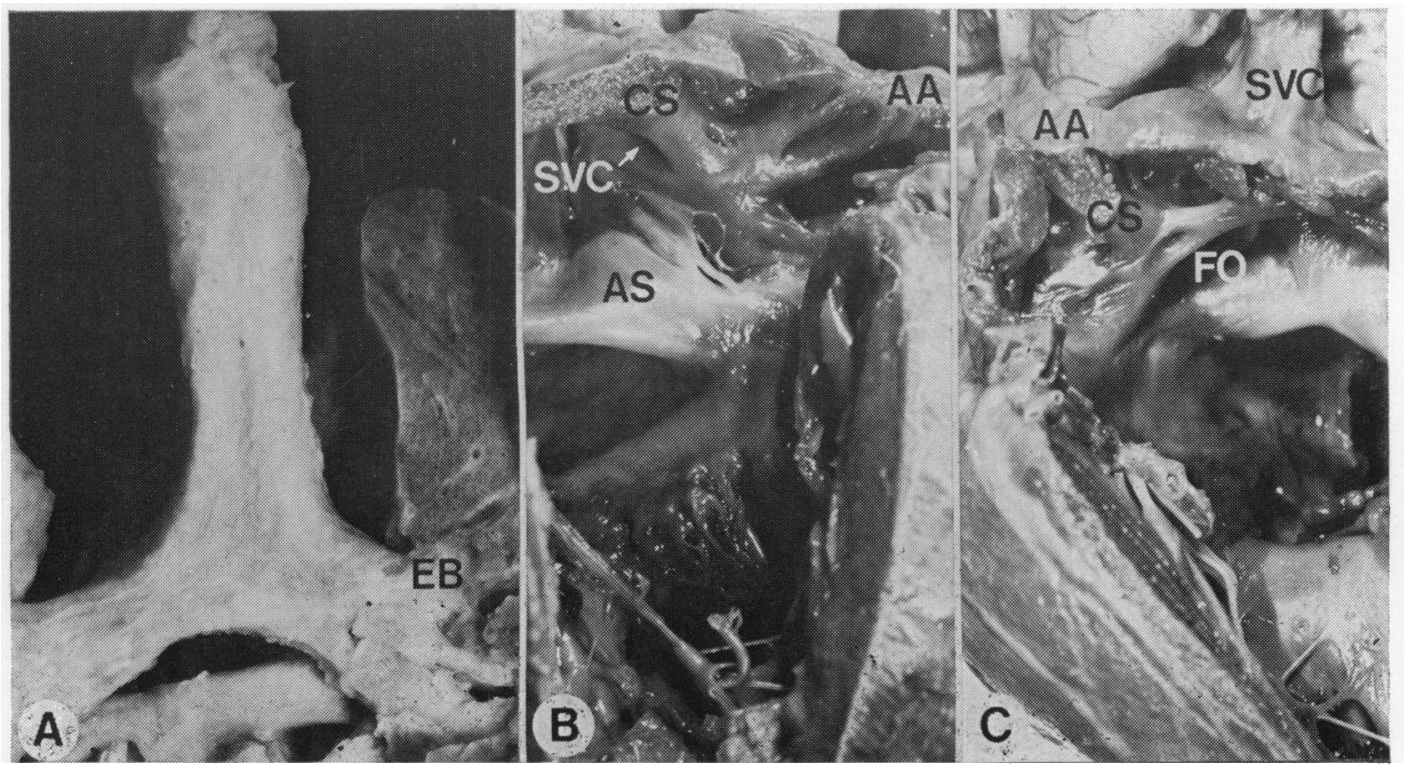

Fig. 2 Case 2. (A) The tracheobronchial bifurcation viewed from posterior. There is an eparterial bronchus $(E B)$ on the right. $(B)$ The opsned right side of the heart. The atrial appentage $(A A)$ on this side shows the internal arrangement of a morphological right atrium. A crista supraventricularis $(C S)$ separates the appendage from the main atrial chamber, which receives a right-sided superior caval vein (SVC) and the pulmonary veins (not visible in this view). The atrial septum $(A S)$ has the septum primum on its right-sided aspect. Note the presence of a persistent common atrioventricular canal. $(C)$ The opened left side of this heart. Again, the atrial appendage (AA) shows features of a morphological right atrium and a crista terminalis (CS). $A$ superior (SVC) and inferior (not visible in this view) caval vein enters the left-sided atrium. The atrial septum at this side exhibits the fossa ovalis (FO).

same atrium. The 4 pulmonary veins connected to the left-sided atrium in the usual way. The atrial septum was deficient and was represented only by a thin membrane with thread-like extensions (Fig. 1B and $C$ ). An indication of a limbus was present in the right-sided atrium. The right-sided atrioventricular connection was absent. The right atrium drained by way of a large atrial septal defect of the primum type to the left-sided atrium. The latter connected to a univentricular heart of right ventricular type which carried a minute trabecular pouch of left ventricular type in the posteroinferior wall. The aorta arose from the main chamber; there was pulmonary atresia and hypoplasia of pulmonary arteries fed from the aorta through a persistent tortuous ductus arteriosus.

\section{CASE 2}

A baby boy developed progressive cyanosis shortly after birth. Clinical examination revealed heterotaxy of the abdominal situs, characterised by a symmetrical liver and right-sided stomach. There was laevocardia and pronounced oligaemia of the lung fields. The findings were considered suggestive of the 'asplenia syndrome'. The child developed increasing cyanosis and dyspnoea and died at the age of 6 weeks.

Necropsy confirmed the presence of heterotaxy of the abdominal situs. The spleen was absent. The inferior caval vein ascended to the left of the vertebral column. The thoracic situs appeared normal with a right-sided trilobed lung and bilobed lung on the left. The tracheobronchial anatomy was that of situs solitus with an eparterial bronchus on the right and a hyparterial bronchus on the left (Fig. 2A). The atrial appendages, however, showed an isomeric morphology. Both appendages had the external appearance of a morphological right atrial appendage, an impression endorsed by the internal arrangement showing a crista terminalis on either side with pectinate muscles radiating from it (Fig. 2B and C). In other words a situs solitus morphology of the tracheobronchial tree was associated with a right-sided isomeric morphology of the atrial appendages. There was a right and left-sided superior caval vein, both connecting to the respective atria. The inferior caval vein connected to the left-sided atrium. Four pulmonary 


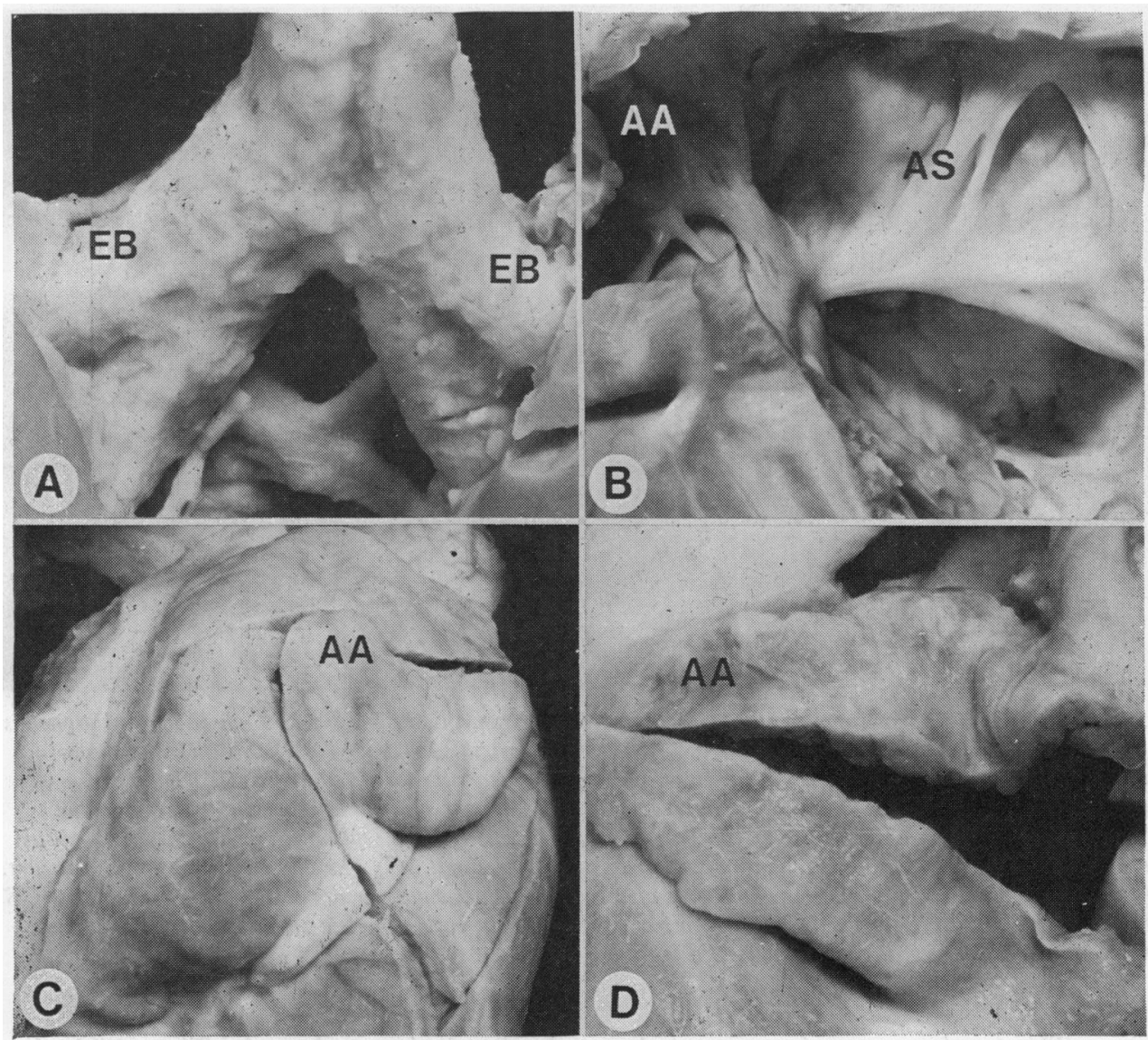

Fig. 3 Case 3. (A) The tracheobronchial bifurcation viewed from posterior. There is an isomeric branching pattern, showing bilateral eparterial bronchi $(E B) .(B)$ The interior of the left-sided atrium. The atrial appendage $(A A)$ has the features of a morphological left atrium; there is no crista terminalis. The atrial septum $(A S)$ has the septum primum on the left-sided aspect. The pulmonary veins (not visible in this view) connected through a common vein to this left-sided atrium. Note the presence of a persistent common atrioventricular canal. $(C)$ The exterior of the right-sided atrial appendage $(A A)$, showing the characteristic shape of a morphological right atrium. (D) The exterior of the left-sided atrial appendage $(A A)$ showing the characteristic shape of a morphological left atrium.

veins connected to the right-sided atrium in an otherwise normal fashion. The 2 atria were separated by an interatrial septum which showed a large primum type defect as part of a persistent common atrioventricular canal of the complete type. The septal anatomy, however, still enabled identification of the limbus of the fossa ovalis on the left side and the septum primum on the right. The coronary sinus was absent. The right-sided atrium connected to a morphologically right ventricle and the leftsided atrium connected to a morphologically left ventricle. The aorta arose from the morphologically right ventricle in an anterior position; the pulmonary trunk was hypoplastic and showed an atretic pulmo- nary ostium, albeit in potential communication with the morphologically left ventricle.

\section{CASE 3}

A baby boy was admitted to hospital immediately after birth because of severe cyanosis. The child was in severe heart failure and died 10 hours after birth.

The necropsy showed heterotaxy of the abdominal organs with a central symmetrical liver and absent spleen. The inferior caval vein ascended on the right side of the vertebral column, but it stayed remote from the hepatic veins which had a separate connection to the atria of the heart (see below). 
The tracheobronchial anatomy revealed a symmetrical bronchial branching pattern with bilateral eparterial bronchi (Fig. 3A). The atrial appendages, however, suggested a situs solitus anatomy with a right-sided atrial appendage showing the characteristics of a morphologically right atrial appendage and a left-sided atrial appendage with the characteristics of a morphologically left atrial appendage (Fig. 3B and C). The atrial septum, moreover, was formed as in situs solitus with the limbus of the fossa ovalis on the right side and the septum primum on the left (Fig. 3D). A large primum atrial septal defect was present, as part of a persistent atrioventricular canal of the complete type. A superior and an inferior caval vein connected to the atrium on the right, while a left-sided superior caval vein and the hepatic veins connected to the leftsided atrium. The pulmonary venous connection was abnormal in the sense that the 4 pulmonary veins were confluent behind the atria and then connected through a common vein to the left-sided atrium. The coronary sinus was missing. The 2 atria connected through a common atrioventricular canal with a univentricular heart of left ventricular type, which carried a small outlet chamber in its right anterior shoulder. The aorta arose from the outlet chamber; the pulmonary ostium was atretic. A right-sided tortuous ductus arteriosus connected the aorta to the pulmonary arteries.

\section{Discussion}

These 3 cases showed a discordancy between the anatomy of the tracheobronchial tree and the morphological features of the atria, though they

Fig. 4 Diagrams of tracheobronchial anatomy and the morphological features that contribute to the identification of atrial situs. ( $A$ ) The usual ('normal') condition. The tracheobronchial anatomy shows an eparterial bronchus on the right; a condition associated with 'situs solitus' of atria. The superior (SVC) and inferior (IVC) caval veins and the coronary sinus (CS) connect to the right-sided atrium, while the pulmonary veins (PV) connect to the left-sided atrium. The atrial septum exhibits the fossa ovalis (FO) on its right aspect, while the left side will show strand-like extensions of the septum primum. The right atrial appendage $(R A A)$ is blunt ending, contains pectinate muscles, and is separated from the remainder of the right atrium by the crista terminalis. The left atrial appendage ( $L A A)$ is slender, 'finger-shaped', does not contain the coarse trabeculations that occur in the right atrial appendage, while a crista terminalis is absent. $(B, C$, and $D)$ The various morphological features of the tracheobronchial tree and the atria are shown schematically as encountered in our cases 1,2 , and 3 , respectively. were inconsistent among themselves (Fig. 4). These observations are of interest since identification of atrial situs is considered the primary step in sequential analysis and categorisation of congenital cardiac malformations (Lev, 1954; Van Praagh et al., 1964a; de la Cruz and Nadal-Ginard, 1972; Van Praagh, 1972; Kirklin et al., 1973; Anderson et al., 1974; Shinebourne et al., 1976; Stanger et al., 1977; Van Praagh, 1977). In most patients with a congenital cardiac anomaly there will be no problem in this respect, since atrial situs will concur with visceral situs. However, there are two conditions in which identification of atrial situs may become difficult. These situations are encountered in patients with a discordancy between the abdominal and thoracic visceral situs and in patients with
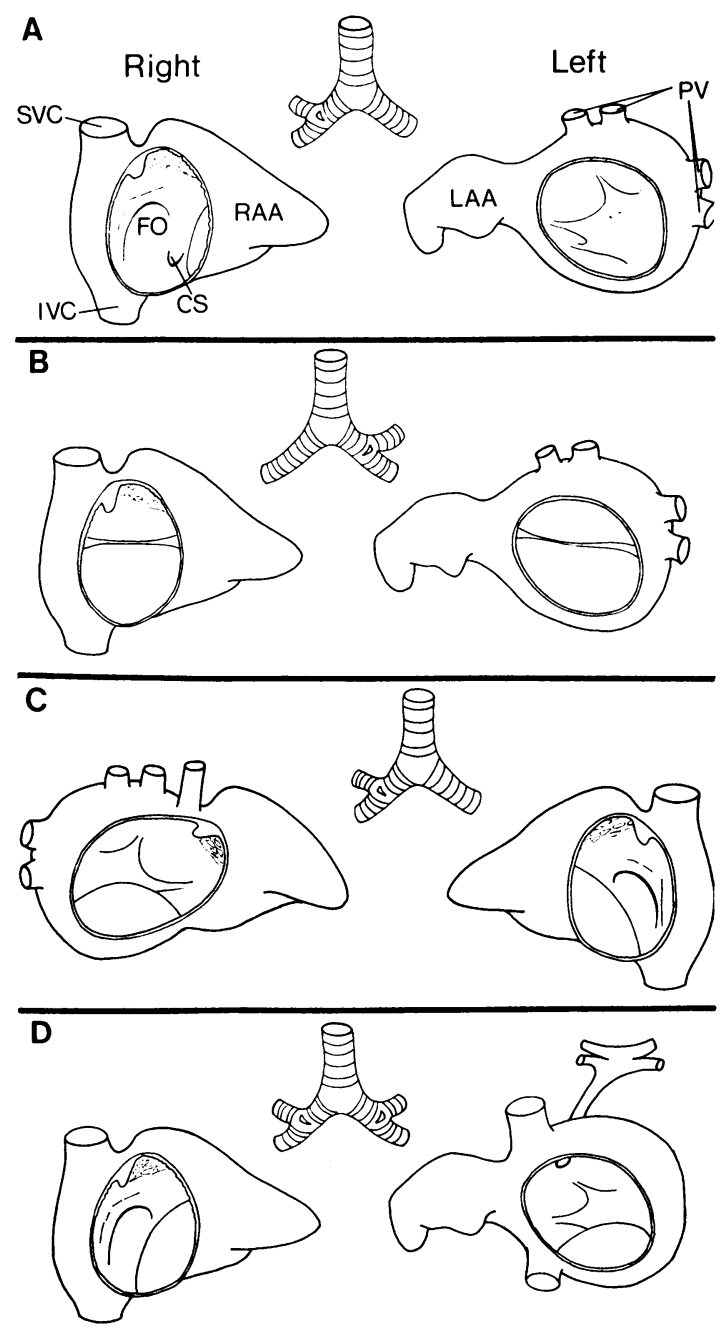
heterotaxy of the abdominal organs. In these circumstances identification of tracheobronchial anatomy has gained much clinical favour (Landing et al., 1971; Partridge et al., 1975), since it is generally accepted that atrial situs will concur with that of the thoracic organs (Van Praagh et al., 1964a; Van Mierop et al., 1970). Thus, in case of a situs solitus or situs inversus morphology of the tracheobronchial tree one may expect the atria to show a situs solitus or a situs inversus morphology, respectively. On the other hand, with a symmetrical bronchial branching pattern, so-called isomerism of the tracheobronchial anatomy, 'atrial isomerism', is to be expected, which in itself may predict the presence of a complex cardiovascular anomaly (Van Mierop et al., 1970, 1972a, b).

In patients with a normal spleen it thus far has only once specifically been stated that the tracheobronchial anatomy and that of the atria were not in accord. The initial report of this patient by Clarkson and associates (1972) documented situs solitus anatomy of the abdominal viscera, associated with dextrocardia, but with inverted anatomy of the atria and atrioventricular discordance. In a subsequent report, Brandt and Calder (1977) specifically stated that the tracheobronchial anatomy was as in situs solitus, that is in accord with that of the abdominal viscera, while the atria showed situs inversus. The latter conclusion was based on the morphology of atrial appendages and the systemic and pulmonary venous connections. Another patient with normal spleen, solitus anatomy of the lungs, laevocardia, and inversus anatomy of atria and abdominal viscera has been reported by Liberthson and co-workers (1973; case 9). However, these authors did not specifically state the bronchial branching pattern in this case.

More exceptions have been described in patients with splenic abnormalities, a condition from which major abnormalities of visceral situs can be predicted (Ivemark, 1955; Van Mierop et al., 1972a, b; Freedom and Fellows, 1973; Stanger et al., 1977). However, the tendency towards a symmetrical development of otherwise unpaired organ systems, which is considered characteristic for these conditions, does not necessarily always occur. In other words, a splenic anomaly is not always accompanied by symmetry of the thoracic organs (Towers and Middleton, 1956, case 1; Lev et al., 1971, cases 7 and 8; Liberthson et al., 1973, cases 1, 4, 12, 16, 19, 25, 29; Rose et al., 1975, 3 cases), and when such isomerism of the tracheobronchial branching pattern is present this is not always associated with symmetry of the atria (Freedom and Fellows, 1973, cases 4, 5, 6; Liberthson et al., 1973, cases 2, 3, 5; Freedom and Harrington,
1974, case 1; Anderson et al., 1976, case 2). Two of our cases (cases 1 and 3), in this respect, endorse previous observations. Our second case is exceptional since it presented a situs solitus anatomy of the tracheobronchial tree, while the atrial appendages showed a morphologically right isomerism. As far as we are aware no cases have as yet been documented of absent spleen with a situs solitus branching pattern of the tracheobronchial tree and isomerism of atrial appendages. The case exemplifies that even in patients with absent spleen recognition of the tracheobronchial anatomy may not always lead to a proper classification of the situs of atria. Of course, the clinical usefulness of the tracheobronchial anatomy as a guide to the classification of atrial situs is by no means invalidated by these observations. They merely underline the fact that a 'rule' cannot be applied as 'law'.

These observations, therefore, necessitate a reconsideration of the criteria employed to identify atrial situs and they raise questions with respect to the terminology to be used.

IDENTIFICATION OF ATRIAL SITUS

The identification of atrial situs depends on a definite recognition of the cardiac chambers as either right or left, itself based on morphological criteria (Lev, 1954; Lev and Rowlatt, 1961). These are the connections of the systemic and pulmonary veins, the anatomical characteristics of the atrial septum, and the external and internal morphology of the atrial appendages. The significance of the atrial septum in identifying atrial situs can be considered of little clinical value, since the anatomical characteristics are not easily recognisable. The value of the venous connections is debatable since these are variable, particularly in congenital heart malformations accompanied by abnormalities in visceral situs. However, the venous connections have the major impact upon the clinical profile of the case and are more likely to be assessed within a clinical setting than is the morphology of the atrial appendages. Indeed, the connection of the inferior caval vein to the atria has been propagated as a reliable and readily obtainable guide to identify the morphologically right atrium in situs solitus and inversus situations (Kirklin et al., 1973; Brandt and Calder, 1977). Our 3 cases seem to support this concept, since the inferior caval vein connected to an atrium which had other characteristics of a morphological right atrium, except that in 1 instance (case 2) the contralateral atrial appendage also showed characteristics of a morphological right atrium. However, it is well known that the course of the inferior caval vein can be abnormal, particularly in cases accompanied by multiple spleens 
(Moller et al., 1967). It is for this reason that we favour a more fundamental approach to the problem of identifying 'right' and 'left' morphological characteristics of atria. As initially suggested by Lev (1954), the basic nature of the atrium, being right or left, will be disclosed by the morphology of its appendage. Strictly speaking, the appendages represent the 'true' atria, while the major part of the definitive atrium is formed by secondary uptake of either sinus venosus tissue or pulmonary veins. One could argue that the anatomy of the atrial appendages has no bearing on the clinical significance of the case and, therefore, should not be promoted as the prime feature for atrial identification. This may be so, but the cases documented in this report exemplify the need for a criterion enabling identification of the 'true' atrial situs in all instances and not dependent upon the venous connections or morphology of the atrial septum. For instance, the first case in our series had a situs inversus anatomy of the tracheobronchial tree, but the venous connections and the morphology of the atrial appendages indicated 'situs solitus'. Should this case be classified as total anomalous systemic and pulmonary venous connections just because the tracheobronchial anatomy suggests situs inversus? We consider this case as an example of 'atrial situs solitus', with a discordant tracheobronchial anatomy taking the morphology of the atrial appendages as the major guide. The second case is of particular interest because the situs solitus morphology of the tracheobronchial anatomy was not in accord with any of the anatomical characteristics which determine atrial situs. Moreover, among themselves these characteristics were in contradiction, since the venous connections and the atrial septum suggested 'situs inversus' but the atrial appendages showed an isomeric right atrial morphology. What determines atrial situs in this case? The clinician diagnosed the atria as having a situs inversus morphology, which he based on the catheter studies. These investigations were carried out over 10 years ago and at that time no particular attempts were made to visualise the tracheobronchial anatomy. However, if this had been attempted before the catheter studies, it seems most likely that an erroneous suggestion of 'situs solitus' would have been forwarded. The necropsy disclosed the isomeric right atrial morphology of the appendages, in itself a common condition in cases of 'asplenia'. In accordance with previous statements we consider that the morphology of the atrial appendages is the final denominator of atrial situs and we, therefore, classify this case as having 'atrial situs ambiguus'. The latter term is then used in the sense of a symmetrical morphology of the atrial appendages, irrespective of the appearance of other criteria for atrial situs.

What to do with the third case, which had bilateral right-sided morphology of the tracheobronchial tree? From this observation 'atrial isomerism' might be expected. However, the atrial appendages did not show a symmetrical morphology. Instead, the right-sided appendage showed characteristics of a morphological right appendage, and the left-sided one showed features of a morphological left appendage, suggesting 'situs solitus'. This supposition was further supported by the morphology of the atrial septum, with a limbus of the fossa ovalis on the right side. However, the venous connections were highly suggestive of 'atrial situs ambiguus', as recently defined (Shinebourne et al., 1976). The case therefore exemplifies the need for a fundamental and pure approach to the classification of situs, particularly when the morphological features among themselves are not in agreement. For reasons outlined above we would like to promote the morphology of the atrial appendages as the prime feature in the identification of atrial anatomy and, hence, for the identification of atrial situs. We do not think that the complexity of atrial anatomy in itself justifies categorisation of atria within a certain type of situs. The terms 'situs ambiguus' and 'situs indeterminatus', in this respect, need further specification.

\section{TERMINOLOGY OF ATRIAL SITUS}

The term 'situs ambiguus' was introduced by Van Mierop et al. in 1970 to indicate, 'that in many patients with asplenia or polysplenia syndrome, the visceral situs cannot be determined because of symmetrical development of normally asymmetrical organs'. Van Mierop, on many occasions, has pointed out that the atria in these conditions cannot be classified as either right or left on anatomical criteria, since both atria show characteristics of either a right or a left atrium (Van Mierop et al., 1964, 1972a, b). He coined the term 'isomerism' to indicate the symmetrical appearance of the atrial appendages under these circumstances (Van Mierop et al., 1964), while other investigators employed the terms 'uncertain' (Van Praagh et al., 1964b) or 'indeterminate' (Lev et al., 1968; Liberthson et al., 1973). The latter observers used the term 'indeterminate' for the situs of the atria when the atrial anatomy was highly abnormal, not necessarily associated with a symmetrical appearance of the atrial appendages. They stated that when the venous connections were highly abnormal and the atrial septum deficient one could not be sure of the situs, irrespective of the anatomy 
of the atrial appendages. Though under those circumstances they considered a 'presumptive diagnosis' of atrial situs, they actually never went so far as to use the morphology of the atrial appendages as a decisive feature for the classification of atrial situs in these complex malformations. In hearts with 'isomerism' of atrial appendages they consequently also use the term 'indeterminate' for atrial situs since situs could not be determined with certainty. Van Mierop, on the other hand, claimed that the morphology of the atrial appendages always enabled their identification, and it was for this reason that he preferred the term 'isomerism' instead of 'indeterminate' (Van Mierop et al., 1964).

Recently, the term 'situs ambiguus' for atria has been proposed (Shinebourne et al., 1976). The authors state that in this situation, 'it is not possible to identify separate right and left atria on morphological criteria. Thus, a common atrial chamber receiving both systemic and pulmonary venous returns is usually associated with bilateral right or left auricular appendages'. We have inferred from this description that the authors use the term also to include conditions in which such a common atrial chamber is present, but not necessarily associated with symmetry of the atrial appendages. Such a definition of 'situs' in our opinion is unfavourable since it permits various interpretations and does not limit itself to the indication of 'situs' but also encompasses additional anomalies. This introduces vagueness where one should be striving for clarity.

When we consider that the morphology of the atrial appendages can always be determined, and as far as we are informed also in a clinical setting, then the term 'situs ambiguus' for atria can be used in a more precise way. Positive identification of the morphology of the atrial appendages will narrow the number of possibilities for atrial situs to 4 . First, there may be situs solitus, with the right atrial appendage on the right and the left atrial appendage on the left. Conversely, there may be situs inversus showing the 'inverted' pattern. Finally, there can be a symmetrical morphology of the atrial appendages, for which the term 'isomeric' seems most appropriate, which can be of either a bilateral right or a bilateral left-sided type. We suggest that the term 'atrial situs ambiguus' be used for those specific conditions only. In other words, the term 'atrial situs ambiguus' is not based upon non-identification, but on pertinent recognition of atrial morphology instead. For a precise description of the type of situs ambiguus one should then indicate whether it is of a bilateral right or a bilateral left-sided characteristic.
We would like to thank Dr R. H. Anderson and Dr G. Losekoot for their critical evaluation of this paper.

\section{References}

Anderson, R. H., Shinebourne, E. A., and Gerlis, L. M. (1974). Criss-cross atrioventricular relationships producing paradoxical atrioventricular concordance or discordance. Their significance to nomenclature of congenital heart disease. Circulation, 50, 176-180.

Anderson, R. H., Smith, A., and Wilkinson, J. L. (1976). Right juxtaposition of the auricular appendages. European fournal of Cardiology, 4, 495-503.

Brandt, P. W. T., and Calder, A. L. (1977). Cardiac connections: the segmental approach to radiologic diagnosis in congenital heart disease. Current Problems in Diagnostic Radiology, 7, No. 3, 1-35.

Clarkson, P. M., Brandt, P. W. T., Barratt-Boyes, B. G., and Neutze, J. M. (1972). "Isolated atrial inversion". Visceral situs solitus, viscero-atrial discordance, discordant ventricular d loop without transposition, dextrocardia: diagnosis and surgical correction. American fournal of Cardiology, 29, 877-881.

de la Cruz, M. R., and Nadal-Ginard, B. (1972). Rules for the diagnosis of visceral situs, truncoconal morphologies and ventricular inversions. American Heart fournal, 84, 19-32.

Freedom, R. M., and Fellows, K.E., Jun (1973). Radiographic visceral patterns in the asplenia syndrome. Radiology, 107, 387-391.

Freedom, R. M., and Harrington, D. P. (1974). Anatomically corrected malposition of the great arteries. Report of 2 cases, one with congenital asplenia: frequent association with juxtaposition of atrial appendages. British Heart fournal, 36, 207-215.

Ivemark, B. I. (1955). Implications of agenesis of the spleen on the pathogenesis of cono-truncus anomalies in childhood. An analysis of the heart malformations in the splenic agenesis syndrome with fourteen new cases. Acta Paediatrica Scandinavica, 44, Suppl. 104, 1-100.

Kirklin, J. W., Pacifico, A. D., Bargeron, L. M., Jun, and Soto, B. (1973). Cardiac repair in anatomically corrected malposition of the great arteries. Circulation, 48, 153-159.

Landing, B. H., Lawrence, T-Y. K., Payne, V. C., Jun, and Wells, T. R. (1971). Bronchial anatomy in syndromes with abnormal visceral situs, abnormal spleen and congenital heart disease. American fournal of Cardiology, 28, 456-462.

Lev, M. (1954). Pathologic diagnosis of positional variations in cardiac chambers in congenital heart disease. Laboratory Investigation, 3, 71-82.

Lev, M., Liberthson, R. R., Eckner, F. A. O., and Arcilla, R. A. (1968). Pathologic anatomy of dextrocardia and its clinical implications. Circulation, 37, 979-999.

Lev, M., Liberthson, R. R., Golden, J. G., Eckner, F. A. O., and Arcilla, R. A. (1971). The pathologic anatomy of mesocardia. American fournal of Cardiology, 28, 428-435.

Lev, M., and Rowlatt, U. F. (1961). The pathologic anatomy of mixed levocardia. A review of thirteen cases of atrial or ventricular inversion with or without corrected transposition. American fournal of Cardiology, 8, 216-263.

Liberthson, R. R., Hastreiter, A. R., Sinha, S. N., Bharati, S., Novak, G. M., and Lev, M. (1973). Levocardia with visceral heterotaxy-isolated levocardia: pathologic anatomy and its clinical implications. American Heart fournal, 85, 40-54.

Moller, J. H., Nakib, A., Anderson, R. C., and Edwards, J. E. (1967). Congenital cardiac disease associated with polysplenia. A developmental complex of bilateral "left-sidedness". Circulation, 36, 789-799. 
Partridge, J. B., Scott, O., Deverall, P. B., and Macartney, F. J. (1975). Visualization and measurement of the main bronchi by tomography as an objective indicator of thoracic situs in congenital heart disease. Circulation, 51, 188-196.

Rose, V., Izukawa, T., and Moës, C. A. F. (1975). Syndromes of asplenia and polysplenia. A review of cardiac and noncardiac malformations in 60 cases with special reference to diagnosis and prognosis. British Heart fournal, 37, 840-852.

Shinebourne, E. A., Macartney, F. J., and Anderson, R. H. (1976). Sequential chamber localization-logical approach to diagnosis in congenital heart disease. British Heart fournal, 38, 327-340.

Stanger, P., Rudolph, A. M., and Edwards, J. E. (1977). Cardiac malpositions. An overview based on study of sixty-five necropsy specimens. Circulation, 56, 159-172.

Towers, B., and Middleton, H. (1956). Congenital absence of the spleen associated with malformations of the heart and transposition of the viscera. Fournal of Pathology and Bacteriology, 72, 553-560.

Van Mierop, L. H. S., Eisen, S., and Schiebler, G. L. (1970). The radiographic appearance of the tracheobronchial tree as indicator of visceral situs. American fournal of Cardiology, 26, 432-435.

Van Mierop, L. H. S., Gessner, I. H., and Schiebler, G. I. (1972a). Asplenia and polysplenia syndrome. In Birth Defects: Original Article Series, 8, no. 1, 74-82.
Van Mierop, L. H. S., Gessner, I. H., and Schiebler, G. I. (1972b). Asplenia and polysplenia syndrome. In Birth Defects: Original Article Series, 8, no. 5, p. 36.

Van Mierop, L. H. S., Patterson, R. R., and Reynolds, R. W. (1964). Two cases of congenital asplenia with isomerism of the cardiac atria and the sinoatrial nodes. American Fournal of Cardiology, 13, 407-414.

Van Praagh, R. (1972). The segmental approach to diagnosis in congenital heart disease. In Birth Defects: Original Article Series, 8, no. 5, p. 4.

Van Praagh, R. (1977). Terminology of congenital heart disease. Glossary and comments. Circulation, 56, 139-143.

Van Praagh, R., Ongley, P. A., and Swan, H. J. C. (1964a). Anatomic types of single or common ventricle in man: morphologic and geometric aspects of 60 necropsied cases. American fournal of Cardiology, 13, 367-386.

Van Praagh, R., Van Praagh, S., Vlad, P., and Keith, J. D. (1964b). Anatomic types of congenital dextrucardia. Diagnostic and embryologic implications. American fournal of Cardiology, 13, 510-531.

Requests for reprints to Dr A. E. Becker, Department of Pathology, Wilhelmina Gasthuis, Eerste Helmersstraat 104, Amsterdam, The Netherlands. 